\title{
Factors influencing quality of academic research: perception of faculty researchers at Oman Medical College
}

\author{
Jahan $F^{1}$, Siddiqui MA², Khabouri ZAl ${ }^{3}$, Riyami RFMAl ${ }^{3}$ and Ahuja $A^{4 *}$ \\ ${ }^{1}$ Department of Family Medicine, Oman Medical College, Oman \\ ${ }^{2}$ Professional Faculties, University of Calgary, Canada \\ ${ }^{3}$ Medical Student, Oman Medical College, Oman \\ ${ }^{4}$ Department of Pharmacy, Oman Medical College, Oman
}

\begin{abstract}
There is a need for academic research in medical schools as it helps in teaching and clinicians' ability to improve practice outcomes. Improvement in patient outcomes is often linked to the ability of physicians to change and adopt new practices within their health care settings. This study explores factors that may affect the quality of research as well as some possible ways for promoting quality research and understanding barriers for doing quality research. A cross sectional study was carried out at Oman Medical College (OMC) on Medicine and Pharmacy faculty. Data was collected using a structured self-filled questionnaire. Survey questionnaire had four components. Statistical analysis was performed using SPSS (IBM SPSS Statistics 24.0). Data was expressed in frequencies from the questionnaire responses which were calculated for all the variables as numbers and percentages. Independent sample t-test was used to compare differences between the two groups using Parametric data. Mann-Whitney test was used to compare differences between the two groups using non-parametric (not normally distributed) continuous data. Forty-two teaching faculties participated in the present study. Faculty experience about generating research idea on their own was $57 \%$ where as proposal writing was 54\%. Minimum experience in grant proposal writing was 59\% where as experience in publishing was 54\% and scholarly presentation was $49 \%$. Institutional factors affecting research were statistical support (51\%), formal supervision and training (47\%) ( -0.147 ; $95 \%$ CI $-2.89-18.51)$. Significant difference was seen with previous research training (mean rank score 24.63) and without any previous research training (mean rank score 16.41) responses $(\mathrm{p}<0.035)$. Teacher researcher showed positive perception and importance of research in effective teaching and practice. Research is an integral part of the teaching practice and professional development. Research training and skill, financial support, technical and logistic support, mentorship and team-work are the main factors affecting quality academic research. The results of this study will be helpful to design the professional development activities and more effectively incorporate active learning into the curriculum.
\end{abstract}

\section{Introduction}

Effective and informed physicians in practice strive to meet the challenge of achieving a high-quality health care system. An evidence based educational system that understands the processes of teaching, learning and practice, impact positively on teaching quality and academic research [1]. This understanding and innovation comes from research in medical education. Medical education research is focused on the education and development of clinicians across the medical training process and continuing professional development (CPD) [2].

Medical education research is mandatory for clinical academics which often has the positive relation between academic research and teaching [3-4]. Academic research improves the processes and outcomes of physician education and training which impact and improve quality education [5-7]. The quality of teaching in Higher Education Institution (HEIs) is strongly connected to research which plays a significant role in shaping the teaching and learning process. It is very important to have nexus between research and teaching. When the research is based on teaching it will provide hands on implications for other teachers [8-9]. Academic research remains a prime source of knowledge and innovation which develops their academic reputation and standards.

The idea of research-teaching nexus is one the of mission goals of Oman medical college (OMC). It is important to ensure quality of research in HEIs by adopting international models used in assessing research quality and address factors which could affect the quality of academic research and publications.

OMC is the first private Health Sciences College in Oman and was established in 2001. The College offers 7-year MD (Doctor of Medicine) and a 5-year B Pharm (Bachelor of Pharmacy) programs. The curriculums for MD and B. Pharm courses have been developed in academic partnership with West Virginia University, USA and have been approved by the Ministry of Health and the Ministry of Higher Education. Teaching and learning strategies at OMC include integrated components of large class format, tutorials, lab work, problem based learning and clinical skills. This study explores teacher researchers' views about factors that may affect the quality of research and what makes quality research and academic publications.

\section{Methodology}

A cross sectional study was conducted at Oman Medical College. All full time as well as part time teaching faculties of Pharmacy, basic

Correspondence to: Alka Ahuja, Professor of Pharmaceutics and Head of Research Oman Medical College, Muscat, Oman, E-mail: alka@omc.edu.com

Key words: academic research, medical faculty, quality of research, teaching

Received: January 03, 2018; Accepted: January 23, 2018; Published: January 26, 2018 
and clinical sciences who consented to participate were included in the study. Data collection was carried out using a structured selfadministered questionnaire, especially designed for this study. Survey instrument was made after literature search which was further reviewed by and agreed on after several brain storming sessions and understanding, so that the questionnaire would maximize the response rates. Questionnaire was distributed to the faculty after validating the questionnaire for its design and length by carrying out a pilot study on five faculty members.

The questionnaire was prepared and approved by the Research and ethical review committee of Oman Medical college. Participants were enrolled after taking written informed consent. The principal investigator ensured uniformity and two trained research assistants assisted principal investigator in data collection. A questionnaire was designed comprising of four sections. The first section consisted of demographic details of the participants. Section two contained questions about faculty perception regarding institutional factors affecting quality of research. Section three was about faculty personal experience and perception about research.and fourth section was about the factors or barriers influencing the quality of academic research.

Statistical analysis was performed using SPSS (IBM SPSS Statistics 24.0). Data was expressed as frequencies for questionnaire responses calculated for all variables in numbers and percentages. Independent sample t-test was used to compare differences between two groups with parametric data and Mann-Whitney test was used to compare differences between two groups with non-parametric (not normally distributed) continuous data.

\section{Results}

A total of 42 faculty members participated in the study out of which 21 (50\%) were males and majority were aged below 50 years. Among all participants, 11 (26.2\%) were PhD qualified and 10 (23.8\%) were MDs (Table 1). Nearly two third of participants had teaching/ research experience of more than 5 years and about one quarter of the participants had published 1-5 research articles. Half of the participants had received formal teaching training and $61.9 \%$ study participants had received formal research training.

Participants were asked multiple questions about perception regarding institutional factors affecting quality of research. Nearly one third of participants disclosed that annual appraisal/ assessment is not effective for their progress on research and nearly half of the participants felt that timely feedback was effective to promote their research (Table 2). More than half of the participants, identified that quality of their program (MD/Pharma), quality of teaching by other faculty in their program, quality of their research experience and library resources/ data base to support research and education affected their quality of research. No significant statistical difference was observed between males (mean score 66.9) and females (mean score 59.1) responses of participants involving perception regarding institutional factors affecting quality of research ( $\mathrm{p}=0.147 ; 95 \%$ CI $-2.89-18.51)$. Similarly, there was no significant difference in the responses of participants with previous research training (mean score 60.77) and without any previous research training (mean score 66.63) $(\mathrm{p}<0.273$; 95\% CI -16.62-4.91).

In the questionnaire, participants were asked regarding their personal experience and perception about research. More than half of the participants thought that their personal experience was effective in generating research ideas, literature search/ search engines/ keywords and critical review of literature. On the other hand, more than fifty
Table 1. Participants Baseline Characteristics

\begin{tabular}{|c|c|c|}
\hline & Frequency & Percent \\
\hline \multicolumn{3}{|l|}{ Gender } \\
\hline Male & 21 & 50.0 \\
\hline Female & 21 & 50.0 \\
\hline \multicolumn{3}{|l|}{ Age } \\
\hline$<30$ & 1 & 2.4 \\
\hline $30-40$ & 13 & 31.0 \\
\hline $40-50$ & 18 & 42.9 \\
\hline $50-60$ & 5 & 11.9 \\
\hline$>60$ & 5 & 11.9 \\
\hline \multicolumn{3}{|l|}{ Programme } \\
\hline Clinical & 11 & 26.2 \\
\hline MD Programme & 10 & 23.8 \\
\hline Pharmacy & 12 & 28.6 \\
\hline Pre-clinical & 2 & 4.8 \\
\hline Pre-medical & 7 & 16.7 \\
\hline \multicolumn{3}{|l|}{ Qualification } \\
\hline Arab Board & 2 & 4.8 \\
\hline MD & 10 & 23.8 \\
\hline MRCGP & 3 & 7.1 \\
\hline $\mathrm{PhD}$ & 11 & 26.2 \\
\hline Others & 16 & 38.1 \\
\hline \multicolumn{3}{|l|}{ Experience } \\
\hline$<5$ years & 9 & 21.4 \\
\hline $5-10$ years & 18 & 42.9 \\
\hline$>10$ years & 15 & 35.7 \\
\hline \multicolumn{3}{|c|}{$\begin{array}{c}\text { Publications as a First } \\
\text { Author }\end{array}$} \\
\hline 0 & 13 & 31.0 \\
\hline $1-5$ & 11 & 26.2 \\
\hline $5-10$ & 4 & 9.5 \\
\hline $10-15$ & 5 & 11.9 \\
\hline $15-20$ & 2 & 4.8 \\
\hline$>20$ & 7 & 16.7 \\
\hline \multicolumn{3}{|c|}{ Formal Research Training } \\
\hline No & 16 & 38.1 \\
\hline Yes & 26 & 61.9 \\
\hline \multicolumn{3}{|c|}{ Formal Teaching Training } \\
\hline No & 21 & 50.0 \\
\hline Yes & 21 & 50.0 \\
\hline
\end{tabular}

percent of participants thought that their personal experience was not effective in receiving grant from funding agencies, publishing books/ contributing chapters and public presentations on awareness of several health issues (Table 3). These study results revealed that no significant statistical difference was observed between males (mean score 68.14) and females (mean score 71.24) responses of participants involving personal experience and perception about research $(p=0.636 ; 95 \%$ CI -16.25-10.07). Similarly, there was no significant difference in the responses of participants with previous research training (mean score 72.27) and without any previous research training (mean score 65.5) (p $<0.294$; 95\% CI -6.11-19.65).

Participants were asked about factors or barriers which affected quality of research. Their responses were in the scale of 1 to 5 (1 indicated no effect and 5 indicated maximum effect). More than half of the participants revealed that research training and skill, financial support, technical and logistic support, mentorship and team-work were the main factors affecting quality academic research (Table 4). No significant statistical difference was observed between males (mean rank score 20.17) and females (mean rank score 22.83) responses of 
Table 2. Faculty perception regarding institutional factors affecting quality of research (1- minimal effect to 5- maximum effect).

\begin{tabular}{|c|c|c|c|c|c|}
\hline & 1 & 2 & 3 & 4 & 5 \\
\hline Annual appraisal/ assessment is effective for your progress on research & $16(38.1)$ & $5(11.9)$ & $6(14.3)$ & $11(26.2)$ & $4(9.5)$ \\
\hline Timely feedback is effective to promote your research & $10(23.8)$ & $4(9.5)$ & $6(14.3)$ & $17(40.5)$ & $5(11.9)$ \\
\hline Formal supervision and evaluation promotes research & $7(16.7)$ & $4(9.5)$ & $7(16.7)$ & $16(38.1)$ & $8(19)$ \\
\hline Opportunities to teach and research in a variety of academic environments & $8(19)$ & $5(11.9)$ & $12(28.6)$ & $11(26.2)$ & $6(14.3)$ \\
\hline Quality of your program (MD/Pharma) & $2(4.8)$ & $7(16.7)$ & $12(28.6)$ & $11(26.2)$ & $10(23.8)$ \\
\hline Quality of teaching by other faculty in your program & $6(14.3)$ & $3(7.1)$ & $9(21.4)$ & $19(45.2)$ & $5(11.9)$ \\
\hline Quality of your research experience & $3(7.1)$ & $3(7.1)$ & $12(28.6)$ & $14(33.3)$ & $10(23.8)$ \\
\hline The intellectual environment and liveliness of your program & $1(2.4)$ & $8(19)$ & $7(16.7)$ & $18(42.9)$ & $8(19)$ \\
\hline Library resources/ data base to support research and education & $1(2.4)$ & $7(16.7)$ & $9(21.4)$ & $15(35.7)$ & $10(23.8)$ \\
\hline Adequate space for interaction with students for joint research & $8(19)$ & $8(19)$ & $9(21.4)$ & $12(28.6)$ & $5(11.9)$ \\
\hline Work space for research /facilities & $8(19)$ & $11(26.2)$ & $9(21.4)$ & $8(19)$ & $6(14.3)$ \\
\hline Formal training for proposal writing & $5(11.9)$ & $5(11.9)$ & $12(28.6)$ & $16(38.1)$ & $4(9.5)$ \\
\hline Institutional research review board & $7(16.7)$ & $4(9.5)$ & $10(23.8)$ & $13(31)$ & $8(19)$ \\
\hline Statistical support & $9(21.4)$ & $5(11.9)$ & $10(23.8)$ & $12(28.6)$ & $6(14.3)$ \\
\hline Laboratory/equipment & $10(23.8)$ & $9(21.4)$ & $9(21.4)$ & $8(19)$ & $6(14.3)$ \\
\hline Visibility and coherence to communities & $8(19)$ & $9(21.4)$ & $10(23.8)$ & $12(28.6)$ & $3(7.1)$ \\
\hline Coordination with policy makers & $10(23.8)$ & $5(11.9)$ & $15(35.7)$ & $9(21.4)$ & $3(7.1)$ \\
\hline High-capacity/high speed communication networks (internet) & $3(7.1)$ & $6(14.3)$ & $8(19)$ & $14(33.3)$ & $11(26.2)$ \\
\hline Funding of research & $7(16.7)$ & $8(19)$ & $11(26.2)$ & $10(23.8)$ & $6(14.3)$ \\
\hline $\begin{array}{l}\text { Faculty members whom you consider mentors and seek advice about } \\
\text { education, career development }\end{array}$ & $8(19)$ & $4(9.5)$ & $11(26.2)$ & $12(28.6)$ & $7(16.7)$ \\
\hline
\end{tabular}

Table 3. Faculty Researchers Personal Experiences and Perception about research (1- minimal effect to 5- maximum effect).

\begin{tabular}{|c|c|c|c|c|c|}
\hline & 1 & 2 & 3 & 4 & 5 \\
\hline Generating research ideas & $5(11.9)$ & $3(7.1)$ & $11(26.2)$ & $14(33.3)$ & $9(21.4)$ \\
\hline Literature search/ search engines/ keywords & $4(9.5)$ & $2(4.8)$ & $14(33.3)$ & $15(35.7)$ & $7(16.7)$ \\
\hline Critical review of literature & $3(7.1)$ & $7(16.7)$ & $11(26.2)$ & $12(28.6)$ & $9(21.4)$ \\
\hline Designing a research study & $2(4.8)$ & $5(11.9)$ & $11(26.2)$ & $17(40.5)$ & $7(16.7)$ \\
\hline Sample size calculation and basic statistics & $3(7.1)$ & $6(14.3)$ & $19(45.2)$ & $7(16.7)$ & $7(16.7)$ \\
\hline Writing and presenting a research proposal & $3(7.1)$ & $4(9.5)$ & $11(26.2)$ & $16(38.1)$ & $8(19)$ \\
\hline Writing grant proposals & $7(16.7)$ & $9(21.4)$ & $12(28.6)$ & $9(21.4)$ & $5(11.9)$ \\
\hline Receiving grant from funding agencies & $16(38.1)$ & $9(21.4)$ & $8(19)$ & $5(11.9)$ & $4(9.5)$ \\
\hline Analyzing and interpreting data & $1(2.4)$ & $3(7.1)$ & $16(38.1)$ & $16(38.1)$ & $6(14.3)$ \\
\hline Oral and poster presentation in conferences & $5(11.9)$ & $6(14.3)$ & $9(21.4)$ & $9(21.4)$ & $13(31)$ \\
\hline Knowledge about impact factor/citation index/ResearchGate scores & $2(4.8)$ & $6(14.3)$ & $12(28.6)$ & $10(23.8)$ & $12(28.6)$ \\
\hline Submission of an article for publication & $5(11.9)$ & $3(7.1)$ & $9(21.4)$ & $12(28.6)$ & $13(31)$ \\
\hline Publishing articles on professional interest and teaching methodologies & $2(4.8)$ & $9(21.4)$ & $9(21.4)$ & $13(31)$ & $9(21.4)$ \\
\hline Publishing books/ contributing chapters & $16(38.1)$ & $7(16.7)$ & $9(21.4)$ & $6(14.3)$ & $4(9.5)$ \\
\hline Invited speaker & $11(26.2)$ & $6(14.3)$ & $13(31)$ & $10(23.8)$ & $6(14.3)$ \\
\hline Presentation for public on awareness of several health issues & $11(26.2)$ & $10(23.8)$ & $9(21.4)$ & $8(19)$ & $4(9.5)$ \\
\hline Invited panelist & $13(31)$ & $6(14.3)$ & $11(26.2)$ & $9(21.4)$ & $3(7.1)$ \\
\hline Key note speaker & $18(42.9)$ & $6(14.3)$ & $10(23.8)$ & $6(14.3)$ & $2(4.8)$ \\
\hline Reviewing articles for journals & $9(21.4)$ & $6(14.3)$ & $10(23.8)$ & $10(23.8)$ & $7(16.7)$ \\
\hline Member of Editorial boards & $13(31)$ & $3(7.1)$ & $12(28.6)$ & $7(16.7)$ & $7(16.7)$ \\
\hline Supervision of research for students/subordinates & $8(19)$ & $4(9.5)$ & $8(19)$ & $14(33.3)$ & $8(19)$ \\
\hline Awards in research & $22(52.4)$ & $5(11.9)$ & $6(14.3)$ & $5(11.9)$ & $4(9.5)$ \\
\hline Awards in teaching & $14(33.3)$ & $10(23.8)$ & $8(19)$ & $8(19)$ & $2(4.8)$ \\
\hline
\end{tabular}

participants involving factors or barriers which affected quality of research $(\mathrm{p}=0.481)$. However, significant difference was observed in the responses of participants with previous research training (mean rank score 24.63) and without any previous research training (mean rank score 16.41) $(\mathrm{p}<0.035)$.

\section{Discussion}

Good quality research is imperative to effect positive changes in patient care and health care system [10,11]. Quality research could be affected by institutional, international, and logistical factors. Teacher researchers should be aware of the factors influencing quality and innovative research for promoting research culture in Oman [12].
Our two third study participants had teaching experience of more than 5 years. However, only one quarter published research articles. In this study, faculty perception regarding institutional factors affecting quality of research, more than one third felt that communication network had the maximum effect. Half of the participants felt that formal supervision, evaluation and feedback, data base resource had the effect on quality research. The literature also reports the positive relation between institutional infrastructure and effective teaching as well as good quality academic research [13-14]. The institutional factors are important in sustaining quality research produced by teacher researchers. The institution must value research and support teacher researchers to carry out research; this would definitely encourage teachers to produce high quality research [15]. 
Table 4. Barriers/ Factors affecting Quality Academic Research (1- minimal effect to 5- maximum effect)

\begin{tabular}{|c|c|c|c|c|c|}
\hline & 1 & 2 & 3 & 4 & 5 \\
\hline Linked to promotion & $8(19)$ & $3(7.1)$ & $14(33.3)$ & $9(21.4)$ & $8(19)$ \\
\hline Time allotted for Research & $3(7.1)$ & $4(9.5)$ & $17(40.5)$ & $7(16.7)$ & $11(26.2)$ \\
\hline Research training and skill & $3(7.1)$ & $3(7.1)$ & $9(21.4)$ & $16(38.1)$ & $11(26.2)$ \\
\hline Statistical support & $3(7.1)$ & $3(7.1)$ & $16(38.1)$ & $9(21.4)$ & $11(26.2)$ \\
\hline Financial support & $4(9.5)$ & $6(14.3)$ & $6(14.3)$ & $9(21.4)$ & $17(40.5)$ \\
\hline Technical and logistic support such as computer and access to library data base & $2(4.8)$ & $2(4.8)$ & $11(26.2)$ & $12(28.6)$ & $15(35.7)$ \\
\hline Mentorship and team-work & $4(9.5)$ & $6(14.3)$ & $8(19)$ & $10(23.8)$ & $14(33.3)$ \\
\hline Collaboration of research with other institutes & $3(7.1)$ & $4(9.5)$ & $16(38.1)$ & $9(21.4)$ & $10(23.8)$ \\
\hline Language barrier prohibits access to the publication and dissemination & $7(16.7)$ & $4(9.5)$ & $14(33.3)$ & $9(21.4)$ & $8(19)$ \\
\hline International standard for research \& publications & $2(4.8)$ & $5(11.9)$ & $21(50)$ & $8(19)$ & $6(14.3)$ \\
\hline Social recognition in the community & $4(9.5)$ & $7(16.7)$ & $17(40.5)$ & $8(19)$ & $6(14.3)$ \\
\hline Journals impact factor / referred journals & $3(7.1)$ & $6(14.3)$ & $12(28.6)$ & $16(38.1)$ & $5(11.9)$ \\
\hline Quality of editorial board & $2(4.8)$ & $8(19)$ & $9(21.4)$ & $16(38.1)$ & $7(16.7)$ \\
\hline Citation out put & $2(4.8)$ & $6(14.3)$ & $16(38.1)$ & $14(33.3)$ & $4(9.5)$ \\
\hline Selection of Participants/Sample Size & $4(9.5)$ & $1(2.4)$ & $14(33.3)$ & $16(38.1)$ & $7(16.7)$ \\
\hline Applied research /study design & $3(7.1)$ & $6(14.3)$ & $11(26.2)$ & $16(38.1)$ & $6(14.3)$ \\
\hline Appropriateness of Statistical Techniques & $3(7.1)$ & $2(4.8)$ & $19(45.2)$ & $10(23.8)$ & $8(19)$ \\
\hline Appropriate methodology & $2(4.8)$ & $3(7.1)$ & $15(35.7)$ & $12(28.6)$ & $10(23.8)$ \\
\hline Good sampling & $2(4.8)$ & $2(4.8)$ & $13(31)$ & $14(33.3)$ & $11(26.2)$ \\
\hline Applied research questions & $2(4.8)$ & $4(9.5)$ & $9(21.4)$ & $15(35.7)$ & $12(28.6)$ \\
\hline Appropriate interpretation of findings & $2(4.8)$ & $6(14.3)$ & $9(21.4)$ & $13(31)$ & $12(28.6)$ \\
\hline Well-formed rationale & $1(2.4)$ & $2(4.8)$ & $11(26.2)$ & $19(45.2)$ & $9(21.4)$ \\
\hline Clear institutional policy & $2(4.8)$ & $5(11.9)$ & $11(26.2)$ & $11(26.2)$ & $13(31)$ \\
\hline Research questions are worth investigating & $3(7.1)$ & $5(11.9)$ & $11(26.2)$ & $11(26.2)$ & $12(28.6)$ \\
\hline Addressing real problem & $3(7.1)$ & $5(11.9)$ & $9(21.4)$ & $13(31)$ & $12(28.6)$ \\
\hline Lack of research-based learning \&teaching environment & $4(9.5)$ & $7(16.7)$ & $8(19)$ & $14(33.3)$ & $9(21.4)$ \\
\hline Motivational factors such as monetary incentives and career progress & $2(4.8)$ & $7(16.7)$ & $11(26.2)$ & $10(23.8)$ & $12(28.6)$ \\
\hline Personal interest \& commitment & $1(2.4)$ & $4(9.5)$ & $4(9.5)$ & $12(28.6)$ & $21(50)$ \\
\hline
\end{tabular}

Our study showed that more than half of the study participants had experience of generating research idea, literature search, design; interpreting data, oral and poster presentation and nearly one third had experience in submission of an article to the peer reviewed journals. The least experience the participants had was regarding receiving grant, publishing book or being an invited speaker. Participatory action research has the potential to result in acceptable and sustainable educational innovations because it involves the active involvement of all stakeholders affected by these interventions [16].

More than half of the participants of our study felt that research training and skill, financial support, technical and logistics support, mentorship and team-work are the main factors affecting quality academic research. Significant difference was observed in the responses of participants with previous research training and without any previous research training $(\mathrm{p}<0.035)$. This also matches with the Literature report regarding promotion of culture of educational research and scholarship of teaching [17].

Good quality academic research effect on teaching can be influenced by educational leadership programs, faculty development and teaching scholars program. Academic research and publications should be valued and should be linked to promotion and financial rewards. Moreover, quality research helps in teaching as teaching and research go hand in hand in HEIs $[15,18]$. Additionally, research resources should be made available such as books, journals, software, etc. Furthermore, staff members should be trained in skills related to publishing research.

\section{Conclusion}

Teacher researcher values quality research in academics and its importance as an integral part of the teaching practice and professional development. Research training and skill, financial support, technical and logistic support and mentorship and team-work are the main factors affecting quality academic research. The results of this study will be helpful to design the professional development activities and more effectively incorporate active learning into the curriculum.

\section{Conflicts of interest}

There was no conflict of interest to be stated.

\section{Authors contribution}

PI and Co PI wrote the first draft of the article and performed intensive review of literature. All co-authors edited the article continuously, read and approved the final manuscript. All authors read and approved the final manuscript.

\section{References}

1. Cabral, A, Huet I (2014) Assessment of research quality in higher education contribution for an institutional framework. Procedia-Social Behavioral Sciences 116: 1528-1532.

2. Chang D, Nyeu F, Chang H (2014) Balancing quality and quantity to build research universities in Taiwan. Higher Education 70: 251-263

3. Albert M, Laberge S, McGuire W (2012) Criteria for assessing quality in academic research: the views of biomedical scientists, clinical scientists and social scientists High Educ 64: 661-676.

4. Cook DA, Reed DA (2015) Appraising the quality of medical education research methods: the Medical Education Research Study Quality Instrument and the NewcastleOttawa Scale-Education. Acad Med 90: 1067-1076. [Crossref]

5. Berger MC, Martin BC, Don Husereau (2014) A questionnaire to assess the relevance and credibility of observational studies to inform health care decision making: An ISPOR-AMCP-NPC Good Practice Task Force Report. Value in Health 1 7: 143-156 
6. Chen FM, Bauchner H, Burstin H (2004) A Call for Outcomes Research in Medical Education. Acad Med 79: 955-960.

7. Dams J (2009) The use of bibliometrics to measure research quality in UK higher education institutions. Research Quality in Higher Education Institutions 57: 19-32.

8. Chang D, Nyeu F, Chang H (2014) Balancing quality and quantity to build research universities in Taiwan. Higher Education 70: 1-125

9. Mahmood S (2011) Factors affecting the quality of research in education: students' perceptions. Journal of Education and Practice 2: 34-40.

10. Holland DG (2009) Between the practical and the academic. The relation of Mode and Mode 2 knowledge production in developing country. Science, Technology and Human Values 34: 551-572.

11. Hollmann M, Borrell C, Garin O, Fernandez E, Alonso J (2015) Factors influencing publication of scientific articles derived from master's theses in public health. Int $J$ Public Health 60: 495-504

12. Nour-Eldein H, Mansour NM, Abdulmajeed AA (2015) master's and doctoral theses in family medicine and their publication output, Suez Canal University, Egypt. J Family Med Prim Care 4: 162-167.
13. Obuku EA, Lavis JN, Kinengyere A, Mafigiri DK, Sengooba F, et al. (2017) Academic research productivity of postgraduate students at Makerere University College of Health Sciences, Uganda, from 1996 to 2010: a retrospective review. Health Research Policy and Systems 15: 1-30

14. Albert MI, Hodges B, Regehr G (2007) Research in medical education: Balancing service and science. Adv Health Sci Educ Theory Pract 12: 103-115.

15. Ajmi ALS, Holi HAA (2015) Quality Research in Higher Education Institutions in Oman: Some Views of Teacher Researchers. Advances in Language and Literary Studies 6: 1-24

16. A G Mubuuke, B Leibowitz (2013) Participatory action research: The key to successful implementation of innovations in health professions education. African $J$ of Health Profession Education 5: 30-33.

17. Akeef S, Obeidat, Ali Ibrahim A, Hamza Mohammad A (2015) Reprioritizing current research trends in medical education: A reflection on research activities in Saudi Arabia. Medical Teacher 37: S5-S8.

18. Newington L, Metcalfe A (2014) Factors influencing recruitment to research: qualitative study of the experiences and perceptions of research teams. BMC Med Res Methodol 14: 1-10

Copyright: (2018 Jahan F. This is an open-access article distributed under the terms of the Creative Commons Attribution License, which permits unrestricted use, distribution, and reproduction in any medium, provided the original author and source are credited. 